\title{
BMJ Global Health Whose voices should shape global health education? Curriculum codesign and codelivery by people with direct expertise and lived experience
}

\author{
Mariam Sbaiti (D) , ${ }^{1}$ Mike J Streule, ${ }^{2}$ Mervat Alhaffar (D) ,3,4,5 Victoria Pilkington, ${ }^{6,7}$ \\ Melanie Leis (D) , ${ }^{8}$ Shyam Sundar Budhathoki (D) , ${ }^{1}$ Hala Mkhallalati (D) ,,9 \\ Maryam Omar (i) , ${ }^{10}$ Lillian Liu (I) , Amelia Kataria Golestaneh, ${ }^{11}$ Aula Abbara ${ }^{12}$
}

To cite: Sbaiti M, Streule MJ, Alhaffar M, et al. Whose voices should shape global health education? Curriculum codesign and codelivery by people with direct expertise and lived experience. BMJ Global Health 2021;6:e006262. doi:10.1136/ bmjgh-2021-006262

Handling editor Seye Abimbola

- Additional supplemental material is published online only. To view, please visit the journal online (http://dx.doi.org/10. 1136/bmjgh-2021-006262).

MS and MJS are joint first authors.

Received 10 May 2021 Accepted 5 August 2021

Check for updates

(c) Author(s) (or their employer(s)) 2021. Re-use permitted under CC BY-NC. No commercial re-use. See rights and permissions. Published by BMJ.

For numbered affiliations see end of article.

Correspondence to

Dr Mariam Sbaiti;

m.sbaiti@ic.ac.uk

\section{ABSTRACT}

There are contrasting opinions of what global health (GH) curricula should contain and limited discussion on whose voices should shape it. In GH education, those with first-hand expertise of living and working in the contexts discussed in GH classrooms are often absent when designing curricula. To address this, we developed a new model of curriculum codesign called Virtual Roundtable for Collaborative Education Design (ViRCoED). This paper describes the rationale and outputs of the ViRCoED approach in designing a new section of the Global Health Bachelor of Science (BSc) curriculum at Imperial College London, with a focus on healthcare in the Syrian conflict. The team, importantly, involved partners with lived and/or professional experience of the conflict as well as alumni of the course and educators in all stages of design and delivery through to marking and project evaluation. The project experimented with disrupting power dynamics and extending ownership of the curriculum beyond traditional faculty by codesigning and codelivering module contents together with colleagues with direct expertise and experience of the Syrian context. An authentic approach was applied to assessment design using real-time syndromic healthcare data from the Aleppo and Idlib Governorates. We discuss the challenges involved in our collaborative partnership and describe how it may have enhanced the validity of our curriculum with students engaging in a richer representation of key health issues in the conflict. We observed an enhanced self-reflexivity in the students' approach to quantitative data and its complex interpretation. The dialogic nature of this collaborative design was also a formative process for partners and an opportunity for GH educators to reflect on their own positionality. The project aims to challenge current standards and structures in GH curriculum development and gesture towards a GH education sector eventually led by those with lived experience and expertise to significantly enhance the validity of GH education.

\section{INTRODUCTION}

The provision of global health $(\mathrm{GH})$ degrees across the world has exploded since the

\section{Summary box}

- Global health (GH) curricula are often designed solely by academic and teaching staff, yet this contrasts with aspirations for more real equality, which have recently gained momentum in the GH community.

- A focus on inequalities and power asymmetries should not only be included in curricular content, but this should also inform the processes through which curricula are designed.

- We designed and piloted a new model for collaborative and interdisciplinary design and delivery of GH curricula, which explicitly involves colleagues with lived experience.

- This approach may help produce more valid GH education programmes, support self-reflexivity among partners and students, demonstrate moves towards more reflexive practice to students and support progress towards a sector led by educators with relevant lived experience.

millennium. Mostly, these are based in highincome countries (HICs). ${ }^{12}$ These asymmetries result from funding structures in $\mathrm{GH}$ research and education and the broader structural inequalities and colonial legacies between communities and nations. ${ }^{3}$ Crucially for educators, these asymmetries affect knowledge production and ownership. Few entities hold disproportionate and, until recently largely unquestioned, epistemic and normative power in the field. ${ }^{4}$

Operationally, educators have varying assumptions about what a GH curriculum should contain, which is also explained by the multitude of GH definitions. GH practice and research often echo the charity model whereby 'experts' based in HIC institutions solve health issues in LMICs. These 'experts' may lack the contextual understanding to intervene appropriately, while those in LMIC 
settings may lack access to contribute their expertise, creating an 'information problem'. ${ }^{5}$ This paradox is reflected in GH education where many of the people whose health is discussed are ubiquitously absent during the curriculum design and delivery stages.

Partnerships are a common heuristic in GH research and practice, yet these often fall short in their aspirations for equality between partners ${ }^{6}$ with overdue discussions emerging on this. ${ }^{7}$ For instance, one of the most cited definitions of $\mathrm{GH}$, ironically referred to as 'a shared definition' by the authors, was published in The Lancet disregarding doubts expressed by LMIC partners. ${ }^{8}$ Paradoxically, most published articles in the field focus on communicable or tropical diseases in LMICs, disregarding its purported 'global' scope. ${ }^{9}$ We understand GH as defined by multidisciplinary and critical analyses of the geographies of inequalities, rather than by national boundaries. ${ }^{2}$ In this paper, we employ the World Bank's classification of countries by national income, to ensure clarity for a broad readership. ${ }^{10}$ We acknowledge that these terms are based on concepts of development centred on economic growth, disregarding their role in creating and perpetuating inequalities (this also forms the starting point of classroom discussions). Yet, we chose these over other imperfect terms to refer to the key differences between countries benefiting from colonialism and those recovering from colonialism and/or conflict-affected countries.

Partnerships in GH education are surprisingly underexamined in the literature. ${ }^{11}$ While different reference documents exist listing competencies for GH graduates, ${ }^{12}$ their authorship is also skewed towards HIC experts with little discussion on authorship processes and representation. However, we note a promising range of curriculum reviews motivated by new possibilities of online learning during the COVID-19 pandemic ${ }^{13}$; with, for example, a shift towards $75 \%$ of the speakers delivering a GH course at McGill University identifying as 'black, indigenous and people of colour'. ${ }^{14}$ Typically, educators address power asymmetries by including them as curricular content, that is objects of study within learning outcomes. However, discussions in terms of involvement in curriculum design remain particularly limited among GH educators. As the colonial systems of oppression underlying the creation of tropical medicine, and their enduring presence in $\mathrm{GH}$, become more explicitly addressed in classrooms, GH education colleagues are calling for reforms in curricular contents and pedagogy ${ }^{13}$. This is an opportune time to examine $\mathrm{GH}$ education design processes, ${ }^{15}$ in order to address the importance of epistemic power and its role in injustices and the reproduction of Western ways of knowing. ${ }^{16-18}$.

In our experience, $\mathrm{GH}$ educators often compose their curriculum and assessments with limited consultation beyond their higher education institution (HEI) and external examiners. Yet educators who are socially closer to the issues discussed, and people with lived experience who are disproportionately affected by health inequalities, have first-hand expertise of curricular contents. ${ }^{5}$ This is therefore an opportune time to examine $\mathrm{GH}$ education design processes, ${ }^{15}$ in order to address the importance of epistemic power and its role in injustices and the reproduction of Western ways of knowing. ${ }^{16-18}$.

This paper presents a simple model for collaborative educational design used to bring those with lived and first-hand expertise of the Syrian conflict into partnership with educators and students for the Global Health BSc at Imperial College London. This paper is authored by the partners who designed the curriculum and by two students who experienced the curriculum after it was designed. The project aimed to experiment with a new approach to curriculum design, so that our knowledge of power asymmetries informs both GH education contents and the curriculum design processes.

\section{VIRTUAL ROUNDTABLE FOR COLLABORATIVE EDUCATION DESIGN}

A new model of partnership for education design called 'Virtual Roundtable for Collaborative Education Design' (ViRCoED) was developed by lead author (MS) with the aim to create a curriculum through a conversational approach to collaboration. Based on the principle of 'subsidiarity', developed by Abimbola in the context of knowledge relations in $\mathrm{GH}$, decisions about helping others to reach a common good should practically and ethically be taken at the most local scale of an organisation and only deferred distally if necessary. ${ }^{18}$ Teaching academics, or 'knowledge-mongers', use knowledge as an important source of capital in the political economy of HEIs and, thus, engage in placing a value on diverse types of knowledge. The ViRCoED model aims to provide a temporary, formative excursion for $\mathrm{GH}$ educators to experiment with the realities of involving colleagues who, we argue, should eventually become the leaders of GH education.

Based on Abimbola's classification, GH academics are typically distant, foreign or subsidiary positionally and adopt an accepting stance to GH issues. ${ }^{18}$ The intention behind ViRCoED is to let this stance be influenced by those with (more) proximate positions vis-à-vis the community/issue discussed. The primary motivation is the role of epistemic power in perpetuating injustices in $\mathrm{GH}^{16-18}$ and a need to problematise current structures and reward systems in our sector. ${ }^{3}$ This approach builds on experiential learning, a key influencing theory in broader medical curricula, ${ }^{19-21}$ which emphasises the need for learning to be situated within, and interact with the subject content. This project aims to provide practical insights into the idea that for authentic experiential learning in GH education, it is necessary to engage those with lived experience (those that have had direct involvement in the 'everyday' experiences of the GH context) in the education design process. The ViRCoED model was employed to design a new section of the Global Health BSc curriculum at Imperial College London, with 27 


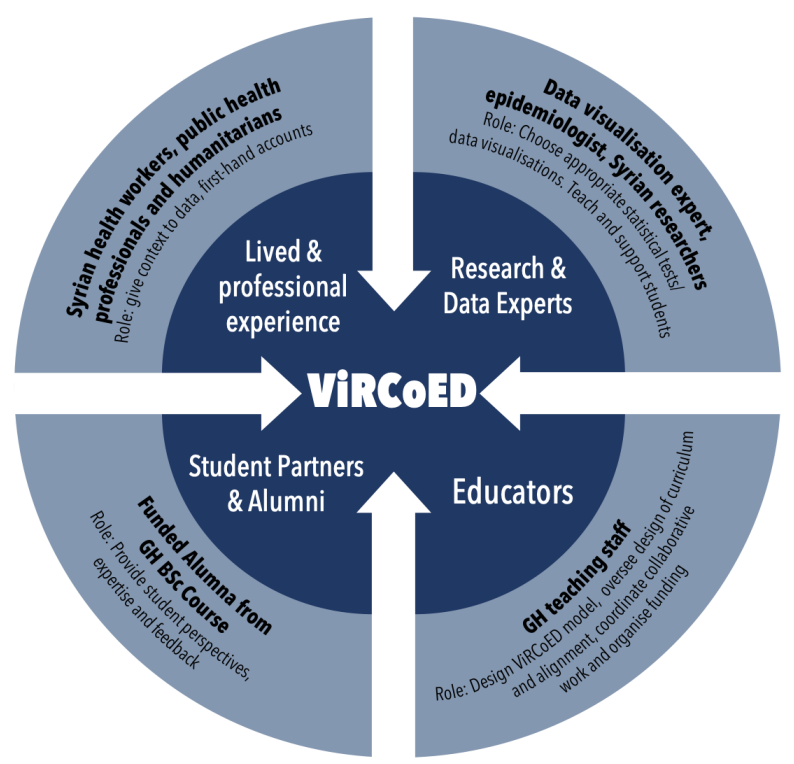

Figure 1 Key stakeholders who contributed to ViRCoED for the curriculum around the Syrian conflict and their roles. ViRCoED, Virtual Roundtable for Collaborative Education Design.

students enrolled. The new curriculum covers learning objectives previously covered through three lectures on humanitarian health and the Syrian conflict, but these were expanded to include more social and historical context of the Syrian conflict and a new assessment was designed ex-novo (accounting for $21 \%$ of the total degree mark). The assessment was redesigned each subsequent year using new, publicly available syndromic surveillance data while learning activities remained unchanged. This section of the curriculum is alongside another ex-novo module codelivered by civil society partners in West London, focusing on issues relating to health inequalities in local communities such as knife crime or child poverty. $^{22}$ This supported the framing of Londoners' health inequalities as $\mathrm{GH}$ issues, as a counternarrative to the fallacy of GH as 'health somewhere else'.

Partners with lived experience and/or professional expertise of the Syrian conflict were invited to participate in the ViRCoED process including Syrian human-rights activists, humanitarians and a British-Syrian doctor and academic working in the NHS/Imperial College London, with extensive humanitarian policy experience in the Syrian crisis. These partners provided a deeper insight into the context of study, and while attempting to achieve a cross-section of the lived experiences, partners were identified through a network of contacts and approaching individuals to collaborate. While this might not represent a perfect process, it nonetheless makes a significant contribution to improved authenticity in the curriculum design process. We assumed that there is no unique 'Syrian experience' and, therefore, no set of partners will represent this. Other partners included an alumna (for student expertise), research methods experts and the educators themselves (figure 1). We also acknowledge that the process whereby educators elect partners to work with reflects educators' own views and circumstances.

During the first roundtable, the course deputy director welcomed partners, shared the ViRCoED concept, invited all partners to engage in leading discussions and the design and delivery of the timetabled sessions and assessment. Beyond this, the process was open to pursue ideas and developments freely towards three team objectives, with some operational limits (time, budget and scope):

1. Define the learning outcomes in the context of the Syrian conflict.

2. Design and deliver learning activities to meet the learning outcomes.

3. Design an aligned, authentic assessment.

A key aim of the project was to create a forum through dialogue in which all partners felt enabled to influence, codesign and deliver module content from the start of the design process and raise any concerns (figure 2). During the first roundtable (duration $\sim 3$ hours), a consensusbased approach to collaborative work was chosen, with discussions around potential challenges, including enduring power differentials.

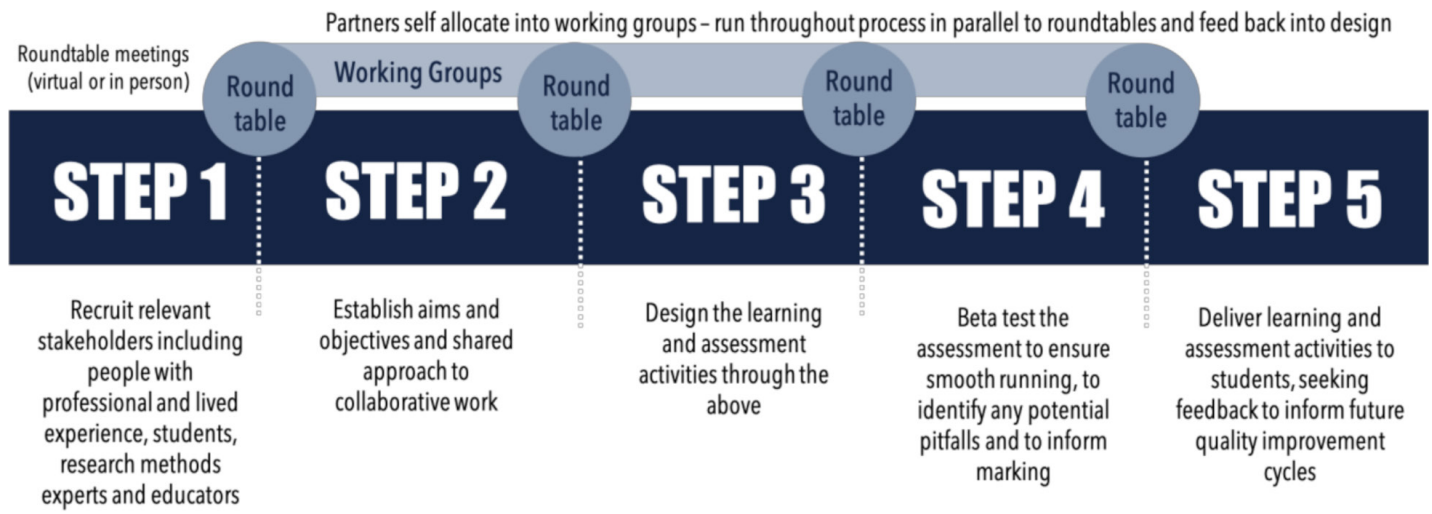

Figure 2 Stages of collaborative work in the ViRCoED model. ViRCoED, Virtual Roundtable for Collaborative Education Design. 


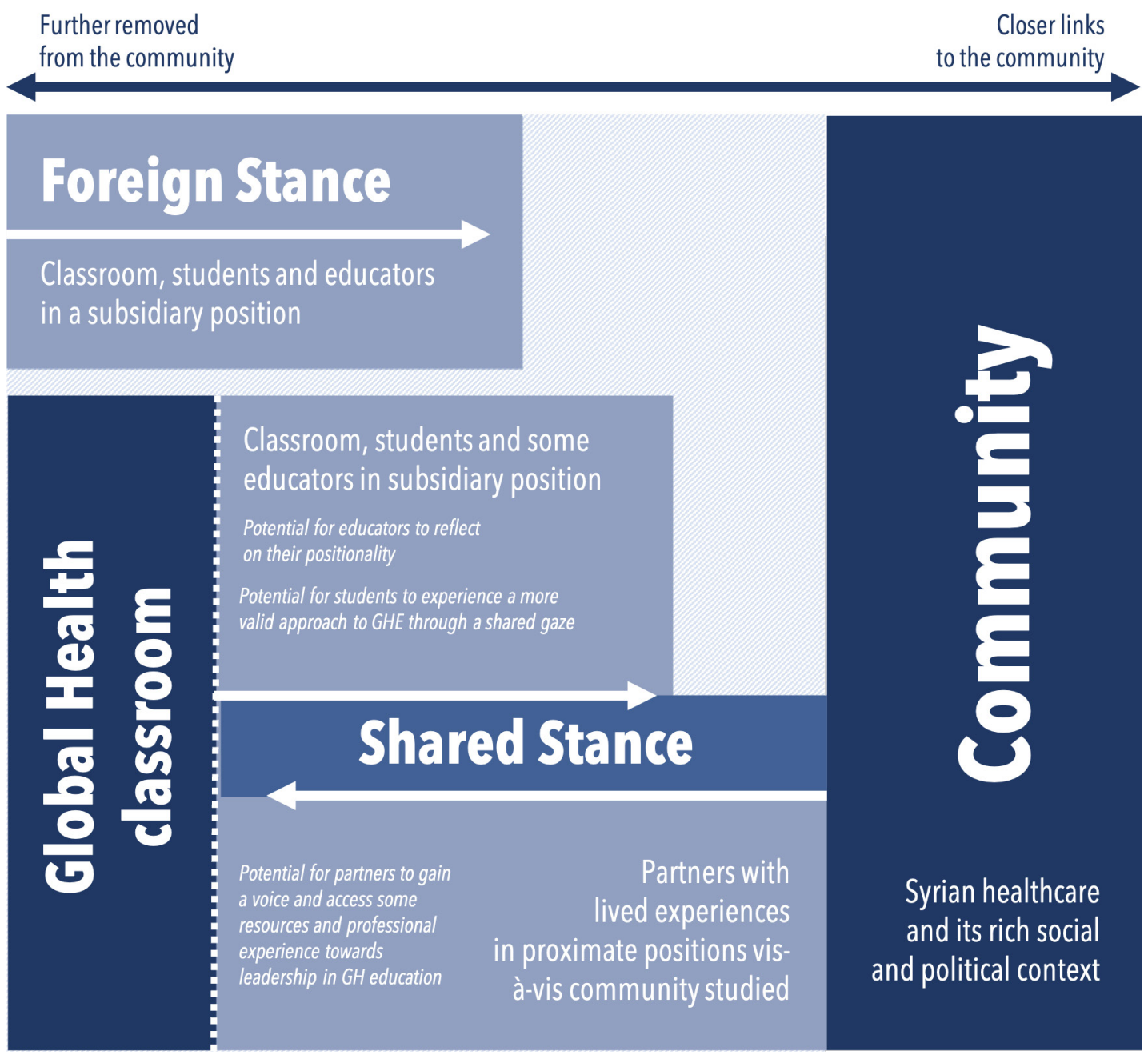

Figure 3 Comparison of the potential differences in stance between business-as-usual and collaborative education design. Collaborative design may result in a shared stance, with some educators sharing their experience as proximate actors in the community (potential advantages for each set of stakeholders).

\section{COLLABORATIVE PARTNERSHIP AND POWER DYNAMICS}

Previous examples of distributing the 'ownership' of medical curricula to stakeholders have been documented. ${ }^{23}$ In the ViRCoED model, we experimented further with the idea that colleagues with lived experience are key stakeholders in creating curricula that are more connected to the context discussed (figure 3). A key partner to this project was AA, who shared her expertise and direct connection to local Syrian organisations and diaspora Syrian public health colleagues. This human connection with the Syrian context disrupted, although temporarily, the otherwise strong subsidiary stances in other parts of the course. For instance, key sessions for students were a 'human library' discussion with a Syrian healthcare worker and human-rights activist and the screening of the film 'For Sama'with panel discussion (figure 4).

Therefore, from a pedagogical and personal perspective, the ViRCoED model may enable GH educators to develop a relationship (albeit distally) with the communities being discussed, while maintaining an inevitably 'subsidiary' position vis-à-vis their realities (figure 3). Through collaborative education design, educators may be able to model attempts towards reflexivity and better inclusivity in their own work, thus contributing to students' meta-learning. ${ }^{24}$ One student partner noted that 'opening the educational stage to external collaborators with lived experience [enables] deeper engagement with global health issues and representation of knowledge'.

Core to our project, and the initial roundtable discussion was the disruption of typical power dynamics around curriculum design processes. However, despite this commitment, the engagement of stakeholders in the project from the outset and the subscribing to a reflexive and critical approach to collaboration, these imbalances were at times challenging. Within our team, there were differences in formal status, job security, pay, academic prestige economies and professional and individual experiences. Some partners were early in their career and new to GH with little or no experience of designing educational activities while others were experts with lived 


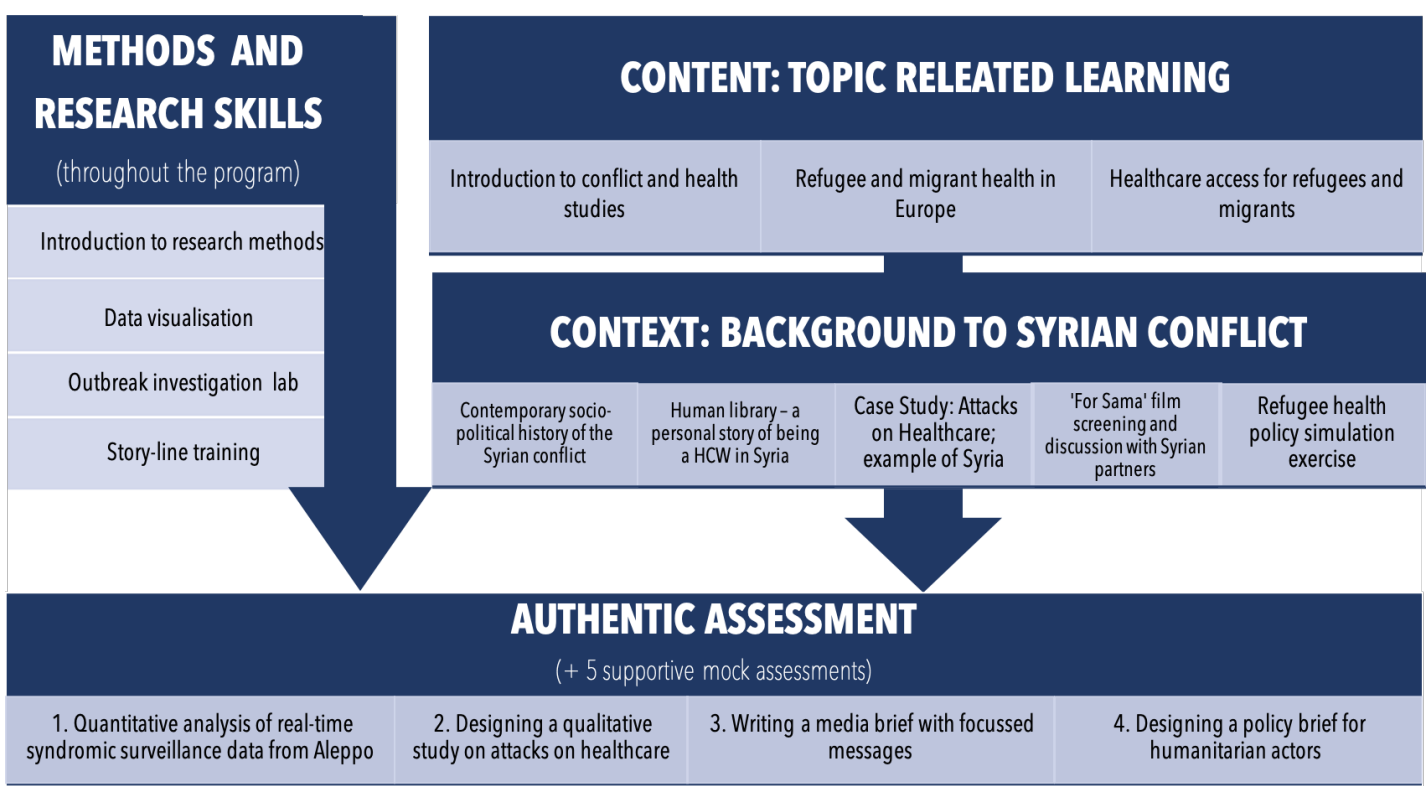

Figure 4 Overview of the multidisciplinary and multi-stakeholder approach to curriculum delivery and how this helps build a richer context for students.

experience and research or education leadership roles. Some partners felt they could contribute more time than others, and while the student partners' engagement was financially supported, no funding for the design stage was available to other partners, who engaged in the project alongside busy schedules. These nuances may have contributed to the perpetuation of perceived power imbalances, generating useful questions about authority and the value of lived experience as expertise. Another challenge was the 'lack of a single leader', with actions often being completed by a couple of team members who had more influence in the project. Therefore, while power dynamics were in some way disrupted, we did not (and did not expect to) reach "equal" status for all partners. ${ }^{25}$ Experimenting with these challenges in such a diverse team, and, thereby, problematising the lack of curriculum ownership by those with lived experience, nonetheless yielded a productive opportunity.

\section{DESIGNING AUTHENTIC AND MULTIDISCIPLINARY LEARNING AND ASSESSMENT}

While key learning outcomes were maintained through to the newly designed sessions (stage 1 ; figure 4 ), these were strongly situated within the Syrian context (stage 2). Due to the research focus of this GH programme, the team designed an assessment (stage 3) based on the principles of authentic learning, in which students analysed publicly accessible near real-time syndromic healthcare data from the Aleppo, and the following year, Idlib governorates. The data were publicly available online in a fully anonymised format with no process of data linkage; therefore, formal ethical review was not required. The assessment integrated this with other tasks including interpreting and communicating suggested findings to a lay audience through a short news piece, producing a draft design for an appropriate qualitative study, and policy recommendations targeted at a specific actor within the relevant humanitarian cluster in SoutWest Turkey (figure 4). This design was chosen to reflect higher level skills, which partners with lived experienced use in their professional lives in the humanitarian and academic sectors. ${ }^{26}$

The assessment was aligned with the learning activities and invited students to conceptualise and evaluate realistic solutions to a public health crisis in an ongoing conflict as well as demonstrate sensitivity and reflexivity in handling data while being socially removed from its context. Three new learning sessions on the geopolitical and humanitarian context in Syria (including one in-depth session on the sociopolitical history of Syria) were included in the timetable. These were delivered by partners with lived experience and experts on attacks on healthcare infrastructure in Syria, healthcare provision during conflict and early warning systems. This supported the students to make sense of the quantitative data, and of the necessity to combine qualitative and quantitative data in GH research. Critical discussions around inconsistencies in data sets collected in conflict settings, unexpected results, how these relate to the context of the data and implications for policy were key learning objectives (figure 4).

Using near real-time data meant that the assessment design stage operated on short timeframes, adding complexity to the process. The data required extensive preanalysis of a near real-time data set within the 2 months prior to the assessment as well as extensive work to create model answers for the formative and summative assessments. Beta-testers were employed to mitigate this and help validate the final assessment briefs (figure 2). Overall, collaborative design required financial 
retributions for some external partners. Educators saw a fivefold increase in the time they spent on assessment design compared with previously.

Partners collaborated in marking assessments, which required additional financial compensation. The availability of partners reduced the time spent on recruiting markers. The marking process itself became easier than business-as-usual design (and potentially more internally valid), as markers were very familiar with the curriculum. In-person independent double marking was conducted to benchmark external collaborators' marking to BSclevel grading through discussion. Course funds were used, as normal, to support this phase of the process.

\section{REFLECTIONS ON OUR APPROACH}

The process was evaluated by student assessment outputs, postcourse student evaluation, by external examiners and through written reflective summaries of partners' engagement in ViRCoED. A key observation was the enhanced self-reflexivity in student assignments, perhaps linked to the humanising and richer experience delivered by partners with lived experience. One common goal was that the conflict became humanised, allowing future doctors to reflect on the complexities of public health in conflict settings. Partners with lived experience also found new opportunities to address misconceptions: 'I found an opportunity to share my lived experience of the Syrian conflict from its very beginning, as counter-narrative to the inaccurate 'civil war' term and other tropes often used by the media'.

Our experience indicates that integrating lived experience, real-world data and real-life outputs may have benefits compared with a more traditional model (figures 3 and 5). A student noted: 'Hearing experiences of Syria on a more personal level humanised the people behind the data'. One student reported that this approach enabled empathy-the conflict went from something in the media, to something that required practical and critical application of analysis skills. A key learning objective was that GH data should not be analysed without understanding its rich context.

We welcome the overdue discussions and awareness within the GH community following the Black Lives Matter movement around the asymmetries in power in our field and their enduring colonial legacies. ${ }^{27}$ These discussions invite $\mathrm{GH}$ educators to imagine a different way of 'doing' GH education. Though business-as-usual education design is dramatically less time-consuming and costly, our experience suggests that this is not conducive to a fairer and more valid GH education sector. In their move towards increased marketisation, HEIs are currently incentivising innovative education and authentic learning. This may explain why we encountered relatively few administrative barriers in this project. HEIs' agendas can provide some windows of opportunity for GH educators to work in this direction. Inevitably, designing authentic curricula collaboratively is demanding as it challenges traditional reward structures in $\mathrm{GH}$ education where limited time is allocated to educational development.

However, our experience shows that collaboration alone does not solve the issues of validity in $\mathrm{GH}$ education, and a commitment to reflexivity is needed in any project. Indeed, we would advise against the ViRCoED

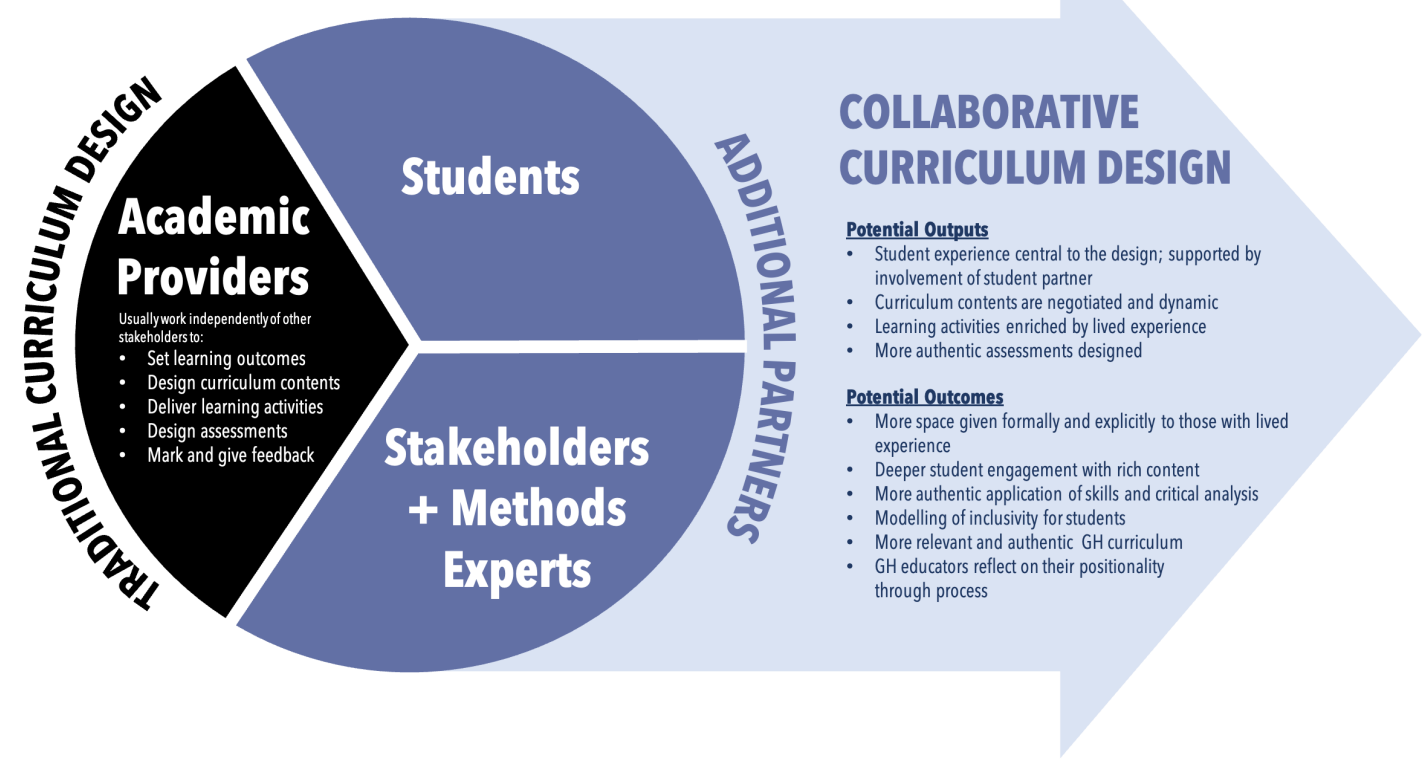

Figure 5 ViRCoED model compared with business-as-usual education design. ViRCoED, Virtual Roundtable for Collaborative Education Design. 
model being employed as another 'technical fix' for GH. To develop ViRCoED further, we would redouble efforts to alleviate power imbalances, providing stronger leadership and more space to discuss and explore these and how they might serve to recognise lived experience as valued expertise. We would also advocate that institutional leaders use collaboration to better align recognitions and rewards in GHE thus creating space for new leadership in the sector.

\section{CONCLUSION}

We developed and piloted a new model for collaborative curriculum design and delivery, which involved reshaping its ownership towards more local users of knowledge. A multidisciplinary team of stakeholders, including colleagues with lived experience, coworked through all stages of curriculum design and delivery, through to marking of assessments and project evaluation. The new curriculum addresses the sociopolitical determinants of health in Syria in a way which is more inclusive, interdisciplinary, experiential and values the expertise of those with lived experience of the conflict. We believe that GH educators should advocate for change, so those with direct, contextualised professional and lived experience are given fair recognition, esteem and reward in education and eventually take the lead in GH education. In the meantime, partnership is essential to the validity of students' learning and has potential to enhance self-reflexivity for educators and meta-learning for students. We invite GH educators and institutions to invest in designing partnerships creatively with physically distant and local communities, while considering power dynamics at the core of their design. In choosing partners for collaborative education, GH educators hold significant power to decide which types of 'local' knowledge and perspectives are given a voice in $\mathrm{GH}$ education. In the longer term, this process needs to be studied and analysed critically.

Beyond enhancing the validity and quality of GH education, collaborations may also provide a formative process for all partners involved. For students, a collaborative approach may help model how educators work explicitly towards addressing injustices in their practice. For GH educators, this means reflecting on the political economy of HE, their power in setting the curriculum and advocating for a more democratic GH education sector.

\footnotetext{
Author affiliations

${ }^{1}$ Department of Primary Care and Public Health, School of Public Health, Imperial College London, London, UK

${ }^{2}$ Centre for Higher Education Research and Scholarship, Imperial College London, London, UK

${ }^{3}$ Department of Global Health and Development, Faculty of Public Health and Policy, London School of Hygiene and Tropical Medicine, London, UK

${ }^{4}$ Syria Research Group, London School of Hygiene and Tropical Medicine, London and National University of Singapore Saw Swee Hock School of Public Health, UK/ Singapore

${ }^{5}$ Department of Infectious Disease Epidemiology, Faculty of Epidemiology and Population Health, London School of Hygiene and Tropical Medicine, London, UK
}

${ }^{6}$ Nuffield Department of Population Health, University of Oxford, Oxford, UK ${ }^{7}$ School of Medicine, Imperial College London, London, UK

${ }^{8}$ Institute of Global Health Innovation, Imperial College London, London, UK

${ }^{9}$ Saw Swee Hock School of Public Health, National University of Singapore, Singapore

${ }^{10}$ Department of Respiratory Medicine, Chelsea and Westminster NHS Foundation

Trust, London, UK

${ }^{11}$ School of Medicine, University of Liverpool, Liverpool, UK

${ }^{12}$ Department of Infectious Disease, Imperial College London, London, UK

Twitter Mariam Sbaiti @mariamthinks, Mervat Alhaffar @SyRG_SCaHR, Melanie Leis@CHP_MelanieL, Shyam Sundar Budhathoki @ShyamSuBu, Hala Mkhallalati @7alaSyr and Maryam Omar@maryam_0m4r

Acknowledgements We thank Dr Aarti Maini for carefully reviewing an early draft of this manuscript. This project was supported by funding from StudentShapers (Imperial College London) to enable partnership with students.

Contributors MS, MA and AA contributed to the concept, design, analysis, review of the literature and interpretation of the data for the paper and the implementation of the project. MJS contributed to the concept, analysis, review of the literature and interpretation of the data for the paper. VP contributed to the concept, analysis and interpretation of the data for the paper and the implementation of the project. SSB, MSL, HM and MO contributed to the concept and design for the paper and the implementation of the project. LL and AKG contributed to the analysis, and review of the literature for the paper and are the partners with experience as students on the course with this curriculum. MS and MJS contributed equally to this paper. All authors contributed to making the first draft, revising and finalising the draft. All authors also take the responsibility for the contents of the paper and have approved the final version submitted for publication.

Funding The authors have not declared a specific grant for this research from any funding agency in the public, commercial or not-for-profit sectors.

\section{Competing interests None declared.}

Patient consent for publication Not required.

Provenance and peer review Not commissioned; externally peer reviewed.

Data availability statement All data relevant to the study are included in the article or uploaded as supplementary information.

Supplemental material This content has been supplied by the author(s). It has not been vetted by BMJ Publishing Group Limited (BMJ) and may not have been peer-reviewed. Any opinions or recommendations discussed are solely those of the author(s) and are not endorsed by BMJ. BMJ disclaims all liability and responsibility arising from any reliance placed on the content. Where the content includes any translated material, BMJ does not warrant the accuracy and reliability of the translations (including but not limited to local regulations, clinical guidelines, terminology, drug names and drug dosages), and is not responsible for any error and/or omissions arising from translation and adaptation or otherwise.

Open access This is an open access article distributed in accordance with the Creative Commons Attribution Non Commercial (CC BY-NC 4.0) license, which permits others to distribute, remix, adapt, build upon this work non-commercially, and license their derivative works on different terms, provided the original work is properly cited, appropriate credit is given, any changes made indicated, and the use is non-commercial. See: http://creativecommons.org/licenses/by-nc/4.0/.

\section{ORCID iDs}

Mariam Sbaiti http://orcid.org/0000-0002-9876-1486

Mervat Alhaffar http://orcid.org/0000-0002-3737-8790

Melanie Leis http://orcid.org/0000-0003-4352-9708

Shyam Sundar Budhathoki http://orcid.org/0000-0002-8614-1087

Hala Mkhallalati http://orcid.org/0000-0002-0347-1137

Maryam Omar http://orcid.org/0000-0003-3519-3706

Lillian Liu http://orcid.org/0000-0001-9294-3433

\section{REFERENCES}

1 Svadzian A, Vasquez NA, Abimbola S. Global health degrees: at what cost? BMJ Glob Heal 2020;5:1-8.

2 Herzig van Wees S, Holmer H, Van Wees SH. Global health beyond geographical boundaries: reflections from global health education. BMJ Glob Health 2020;5:e002583. 
3 Buitendijk S, Ward H, Shimshon G, et al. COVID-19: an opportunity to rethink global cooperation in higher education and research. $B M J$ Glob Health 2020;5:e002790-9.

4 Shiffman J. Knowledge, moral claims and the exercise of power in global health. Int J Health Policy Manag 2014;3:297-9.

5 Abimbola S. The information problem in global health. BMJ Glob Health 2016;1:e900001-6.

6 Gautier L, Sieleunou I, Kalolo A. Deconstructing the notion of "global health research partnerships" across Northern and African contexts. BMC Med Ethics 2018;19:49.

7 Crane JT. Unequal 'Partners'. AIDS, Academia, and the Rise of Global Health. Behemoth2010;3.

8 Adams LV, Wagner CM, Nutt CT, et al. The future of global health education: training for equity in global health. BMC Med Educ 2016;16:1-7.

9 De Cock KM, Simone PM, Davison V, et al. The new global health. Emerg Infect Dis 2013;19:1192-7.

10 Bank W. World bank country and lending groups, 2021. Available: https://datahelpdesk.worldbank.org/knowledgebase/articles/ 906519-world-bank-country-and-lending-groups [Accessed 21.08.2021].

11 Arora G, Russ C, Batra M, et al. Bidirectional exchange in global health: moving toward true global health partnership. Am J Trop Med Hyg 2017;97:6-9.

12 Peluso MJ, van Schalkwyk S, Kellett A, et al. Reframing undergraduate medical education in global health: rationale and key principles from the Bellagio global health education initiative. Med Teach 2017;39:639-45.

13 Atkins S, Banerjee AT, Bachynski K, et al. Using the COVID-19 pandemic to reimagine global health teaching in high-income countries. BMJ Glob Health 2021;6:e005649.

14 Pai M. We can use the pandemic to Reimagine global health teaching, 2021. Available: https://www.forbes.com/sites/ madhukarpai/2021/02/15/we-can-use-the-pandemic-to-reimagineglobal-health-teaching/?sh=5dddaf281710
15 Hommes F, Monzó HB, Ferrand RA, et al. The words we choose matter: recognising the importance of language in decolonising global health. Lancet Glob Health 2021;9:e897-8.

16 Affun-Adegbulu C, Adegbulu O. Decolonising global (public) health: from Western universalism to global pluriversalities. BMJ Glob Health 2020;5:e002947.

17 Shiffman J. Global health as a field of power relations: a response to recent commentaries. Int J Health Policy Manag 2015;4:497-9.

18 Abimbola S. The uses of knowledge in global health. BMJ Glob Health 2021;6:e005802.

19 Maudsley G, Strivens J. Promoting professional knowledge, experiential learning and critical thinking for medical students. Med Educ 2000;34:535-44.

20 Biswas S, Douthit NT, Mazuz K. Implementing a practical global health curriculum: the benefits and challenges of patient-based learning in the community. Front Public Heal2020;8.

21 Kolb DA. Experiential learning: experience as the source of learning and development. Second ed. New Jersey: Pearson Education, 2014.

22 MacKay M. Global Health students and London voluntary sector share community expertise, 2020. Available: https://www.imperial. ac.uk/news/196034/global-health-students-london-voluntary-sector/ [Accessed 16 Jun 2021]

23 Elizondo-Montemayor L, Hernández-Escobar C, Ayala-Aguirre F, et al. Building a sense of ownership to facilitate change: the new curriculum. Int J Leadersh Educ 2008;11:83-102.

24 Jackson * N. Developing the concept of metalearning. Innov Educ Teach Int 2004;41:391-403.

25 Kapadia SJ. Perspectives of a 2nd-year medical student on 'Students as Partners' in higher education - What are the benefits, and how can we manage the power dynamics? Med Teach 2021;43:478-9.

26 Villarroel V, Bloxham S, Bruna D, et al. Authentic assessment: creating a blueprint for course design. Assess Eval High Educ 2018;43:840-54.

27 Abimbola S, Pai M. Will global health survive its decolonisation? Lancet 2020;396:1627-8. 